\title{
ESTUDO DA REAÇÃO DE TRANSESTERIFICAÇÃO DO ÓLEO DE GIRASSOL USANDO EXTRAÇÃO COM SOLVENTE EM DUAS FASES
}

\author{
M. P. de A. MARIN ${ }^{1}$, L. NOVAZZI ${ }^{1}$ e M. L. DENARI ${ }^{1}$ \\ ${ }^{1}$ Centro Universitário da FEI, Departamento de Engenharia Química \\ E-mail para contato: marimari@fei.edu.br
}

\begin{abstract}
RESUMO - Neste projeto estudou-se a extração de óleo de sementes de girassol com hexano, obtendo-se uma mistura de óleo e solvente que foi posteriormente transesterificada com metanol e $\mathrm{KOH}$, em batelada. A reação foi conduzida com temperatura constante de $45^{\circ} \mathrm{C}$, por 1 hora, tendo o hexano papel de co-solvente no meio reacional. Foi analisada nessa reação a influência da relação molar metanol / óleo e da quantidade de catalisador em relação à massa de óleo. O rendimento reacional foi analisado por cromatografia gasosa. Determinou-se que o teor de umidade da semente é de $8,45 \%$ e que o teor de óleo contido na oleaginosa é de $26,5 \%$, sendo necessárias 3,5 horas para se atingir a máxima extração. Fez-se um planejamento fatorial $2^{2}$ de modo que a relação molar metanol / óleo ficou entre 5:1 e 7:1 e as quantidades de catalisador entre $0,75 \%$ e $1,25 \%$. Notou-se que o aumento da relação molar exerce um efeito negativo na conversão, enquanto que o aumento na quantidade de catalisador apresenta efeito positivo. Propôs-se um modelo matemático empírico, que representou bem o rendimento da reação como função da relação molar metanol / óleo e quantidade de catalisador. Para o sistema em estudo, conseguiu-se como maior conversão $34,13 \%$, um valor relativamente baixo. Este fato foi associado com a elevada relação volumétrica do co-solvente com o metanol na reação de transesterificação.
\end{abstract}

\section{INTRODUÇÃO}

A maior parte de toda energia consumida no mundo provém do petróleo, carvão e do gás natural. Entretanto, essas são fontes não renováveis e possuem previsão de esgotamento em um futuro próximo. Além disso, os combustíveis fósseis são muito poluidores afetando o meio ambiente de forma bastante agressiva, o que faz a população mundial buscar soluções para tais problemas.

Como combustíveis alternativos, óleos vegetais começaram a ser estudados no final do século XIX por R. Diesel, sendo que estes eram usados in natura. Contudo, o uso direto nos motores apresenta muitos problemas, como o acúmulo de material oleoso nos bicos de injeção (Knothe et al., 2006). Alternativas têm sido consideradas para melhorar o desempenho de óleos vegetais em motores de ciclo diesel. Dentre elas, a reação de transesterificação tem sido a mais usada, pois um dos produtos obtidos, o biodiesel, possui propriedades similares ao diesel de petróleo com significativas vantagens. 


\section{9 a 22 de outubro de 2014 \\ Florianópolis/SC}

O biodiesel é um combustível renovável e biodegradável constituído de ésteres metílicos ou etílicos de ácidos graxos, obtidos da reação de transesterificação de um triglicerídeo, matéria-prima oleaginosa com um álcool de cadeia curta na presença de um catalisador, como representado pela equação a seguir, na qual $A$ representa o triglicerídeo, $B$ o álcool, $R$ o biodiesel e $S$ indica a glicerina formada.

$$
A+3 B \rightleftarrows 3 R+S
$$

As principais matérias-primas utilizadas para produção de biodiesel são os óleos vegetais refinados ou os semi-refinados, que possuem preço de mercado bastante elevado quando comparados com o preço do biodiesel. Para se ter ideia, quando se utiliza o óleo refinado, o custo da matéria prima representa de 70 a 80\% do custo total de processo (Zang et al., 2003 apud Shi e Bao, 2008) de obtenção de biodiesel. Levando em conta esta desvantagem, muitos trabalhos foram realizados com o objetivo de reduzir custos no processo de produção de biodiesel, tais como seleção de matéria-prima mais barata, aumento da taxa de conversão de reação e simplificação de processos.

São encontrados na literatura muitos trabalhos sobre produção de biodiesel de óleo de reuso, óleo de microalga ou outras matérias primas que apresentam viabilidade para produzir biodiesel de qualidade (Tomasevic e Silver-Marinkovic, 2003; Meher et al., 2006 apud Shi e Bao, 2008). Além destes artigos, são encontrados inúmeros outros trabalhos nos quais são estudadas as condições ótimas de operação para combinação de diferentes ácidos graxos de origem vegetal (óleo de soja, mamona, girassol, etc) com diferentes alcoóis como etanol e metanol (Novazzi et al., 2008; Marin et al., 2008; Santos et al., 2009; etc.). Na maioria destes trabalhos, os óleos utilizados como matéria prima eram óleos refinados.

Para obtenção de óleos vegetais existe a extração de óleo da semente por meios mecânicos, como prensagem ou por extração com solvente. Contudo, a maioria dos óleos vegetais é obtida por meio de extração, pois esta técnica permite o processamento de um grande volume de sementes quando comparado com a extração por prensagem e também produz óleos com menor teor de goma. O processo de refino de óleo é relativamente complexo e apresenta um elevado consumo de energia e materiais, o que resulta num alto custo do óleo vegetal.

Shi e Bao (2008) propuseram produzir biodiesel a partir da solução óleo / hexano, obtida da extração com solvente, com metanol e obtiveram graus de conversão elevado da reação. Esta metodologia representa um grande avanço, pois significa que o biodiesel pode ser produzido sem a etapa da separação do solvente e da etapa de refino do óleo vegetal o que representa uma relativa economia de energia. $\mathrm{O}$ hexano, solvente utilizado na extração, dissolve parcialmente o álcool, sendo assim pode ser usado como co-solvente na reação de transesterificação auxiliando no aumento da taxa de reação (Meher et al., 2006). No trabalho citado, proporções volumétricas como 15:1 e 35:1 entre co-solvente e o álcool auxiliam e favorecem a conversão.

Embora cerca de $80 \%$ do biodiesel no Brasil seja produzido a partir do óleo de soja, neste trabalho foi utilizado o girassol como oleaginosa. O girassol (Helianthus annus L.) é uma oleaginosa que tem se apresentado como uma boa alternativa para a produção de biodiesel, pois sua cultura 


\section{9 a 22 de outubro de 2014 \\ Florianópolis/SC}

apresenta características favoráveis sob o ponto de vista agronômico, como ciclo curto, elevada qualidade e bom rendimento em óleo, cujo teor pode variar entre 38 e $48 \%$ (Guirra, 2009). Neste projeto estudou-se a reação de transesterificação associada a tecnologia de extração com solvente, utilizando semente de girassol e metanol como agente transesterificante em catálise homogênea básica para produção de ésteres metílicos (biodiesel).

\section{MATERIAIS E MÉTODOS}

\subsection{Materiais}

Neste trabalho utilizou-se como matérias-primas semente de girassol, n-hexano P.A. e metanol P.A. ambos da Dinâmica Produtos Químicos Ltda. e hidróxido de potássio (KOH) P.A., em pellets, da Merck. Os equipamentos utilizados são listados a seguir: balança analítica, moinho de facas, estufa a vácuo, manta de aquecimento, agitador mecânico, banho termostático, extrator Soxhlet, vidrarias de laboratório em geral e cromatógrafo gasoso Varian Star 3600 com detector FID.

\subsection{Caracterização da Semente de Girassol}

Determinação da umidade: Para determinação da umidade na semente de girassol, aproximadamente $40 \mathrm{~g}$ de semente moída em moinho de facas até pequena granulometria foi colocada em béquer e levada para a estufa a vácuo a temperatura $70^{\circ} \mathrm{C}$ e seca até massa constante.

Determinação da fração de óleo extraída em função do tempo: Aproximadamente $50 \mathrm{~g}$ de semente de girassol moída e seca foram acondicionadas em cartucho e colocada no extrator Soxhlet com $500 \mathrm{~mL}$ de n-hexano e o sistema submetido a aquecimento. $\mathrm{O}$ sistema ficou em recirculação por 5 horas e ao final de cada ciclo (evaporação do solvente, sifonação) com duração de 10 minutos eram retiradas alíquotas de $10 \mathrm{~mL}$ da solução óleo-hexano. As alíquotas colocadas em béquer eram levadas à capela para evaporação do solvente. Ao fim da evaporação a massa de óleo resultante era medida.

\subsection{Caracterização do Óleo de Girassol}

Os índices de acidez e de saponificação do óleo de girassol, necessários para determinação do ácido graxo livre e também para determinação da massa molar média, foram realizados de acordo com a metodologia proposta pela AOCS (1998). O ensaio 5a-40 refere-se ao índice de acidez (IA) e o ensaio 3b-76 ao índice de saponificação (IS).

\subsection{Reação de Transesterificação}

A reação de transesterificação foi conduzida num reator batelada em vidro de $0,5 \mathrm{~L}$ com três bocas. Na boca central foi acoplado um agitador mecânico e nas outras duas bocas foram colocados respectivamente um termômetro e um condensador de refluxo. O controle da temperatura do sistema foi realizado por um banho termostatizado, com precisão de $0,1^{\circ} \mathrm{C}$. A solução óleo-hexano obtida da extração foi carregada no reator e a temperatura do sistema $\left(45^{\circ} \mathrm{C}\right)$ foi ajustada por meio do banho termostatizado. Paralelo a isto, hidróxido de potássio $(\mathrm{KOH})$ foi dissolvido em metanol. Mantendo-se 
uma rotação de $200 \mathrm{rpm}$, adicionou-se no reator a mistura de álcool e catalisador. A reação foi conduzida por um intervalo de 1 hora. Depois do término da reação, a mistura foi transferida para um funil de separação ficando em repouso por 24 horas, garantindo a separação das fases. Isso resultou na formação de uma fase superior correspondente aos ésteres metílicos, hexano e metanol não reagido e uma fase inferior contendo a glicerina, hidróxido de potássio e sabões formados durante a reação. A fase superior foi separada e levada para a análise cromatográfica que identificou os ésteres metílicos formados.

\subsection{Planejamento Fatorial}

Duas variáveis que afetam o grau de conversão $(y)$ da reação de transesterificação são a relação molar metanol / óleo $\left(x_{1}\right)$ e porcentagem mássica de catalisador em relação a massa de óleo $\left(x_{2}\right)$. Nesse trabalho fez-se um planejamento fatorial $2^{2}$ com ponto central (Bruns et al., 2001), isto é, $x_{1} \mathrm{e}$ $x_{2}$ foram variados em dois níveis diferentes e um ponto central. Na Tabela 1 estão indicados os arranjos experimentais empregados. Os ensaios foram relizados aleatoriamente, de modo que os vértices do arranjo (A, B, C e D) foram executados sem repetição e o ponto central a que se refere o ponto $\mathrm{E}$ foi relizado em triplicata.

Tabela 1 - Condicões experimentais

\begin{tabular}{ccc}
\hline Ensaio & $x_{1}$ & $x_{2} / \%$ \\
\hline A & $5: 1$ & 0,75 \\
B & $7: 1$ & 0,75 \\
C & $5: 1$ & 1,25 \\
D & $7: 1$ & 1,25 \\
E & $6: 1$ & 1,00 \\
\hline
\end{tabular}

O efeito principal da relação molar metanol / óleo, $R$, representa a média dos efeitos desse fator nos dois níveis distintos de quantidade de catalisador e pode ser calculado de acordo com a Equação 1 (Bruns et al., 2001). Por raciocínio análogo, o efeito da quantidade de catalisador, $C$, é determinado utilizando a Equação 2. Já o efeito da interação entre os dois fatores, $R C$, é escrito na Equação 3.

$$
\begin{aligned}
& R=\frac{\left(y_{B}-y_{A}\right)+\left(y_{D}-y_{C}\right)}{2} \\
& C=\frac{\left(y_{C}-y_{A}\right)+\left(y_{D}-y_{B}\right)}{2} \\
& R C=\frac{\left(y_{D}-y_{B}\right)+\left(y_{C}-y_{A}\right)}{2}
\end{aligned}
$$

\subsection{Análise da Conversão da Reação de Transesterificação}

A análise dos ésteres metílicos produzidos no processo foi feito por cromatografia gasosa (CG) utilizando-se o Cromatógrafo gasoso Varian Star 3600 com detector FID e uma coluna DBWAX de $0,25 \mathrm{~mm} \times 60 \mathrm{~m}$ e espessura do filme de $0,25 \mu \mathrm{m}$. A temperatura estabelecida 
inicialmente para a coluna foi de $90^{\circ} \mathrm{C}$ por 1 min seguida por uma taxa de aquecimento de $2^{\circ} \mathrm{C}$. $\min ^{-1}$ até $240^{\circ} \mathrm{C}$. A temperatura do detector foi de $225^{\circ} \mathrm{C}$ e do injetor $250^{\circ} \mathrm{C}$. Para esta análise utilizou-se uma concentração de padrão de 2000 ppm e os ésteres utilizados foram laurato, miristato, palmitato, linolenato, linoleato, oleato e estearato. A injeção das amostras foi realizada com $1 \mu \mathrm{L}$ de amostra e $1 \mu \mathrm{L}$ de ar.

\section{RESULTADOS E DISCUSSÃO}

As sementes de girassol utilizadas no desenvolvimento deste trabalho foram previamente moídas e secas até massa constante (seção 2.2), o que ocorreu depois de 4 horas. Os resultados mostraram um teor de umidade inicial na semente de $8,45 \%$. A etapa de secagem é importante, pois a umidade diminui a velocidade de extração e posteriormente compromete a reação de transesterificação (Brum et al., 2009). Depois da preparação prévia das sementes, realizou-se a extração de óleo com hexano. A partir das amostras de hexano / óleo retiradas do balão, determinouse a fração de soluto extraído, ext, em função do tempo $t$, como indicado na Figura 1. Esses pontos aparecem como círculos no gráfico.

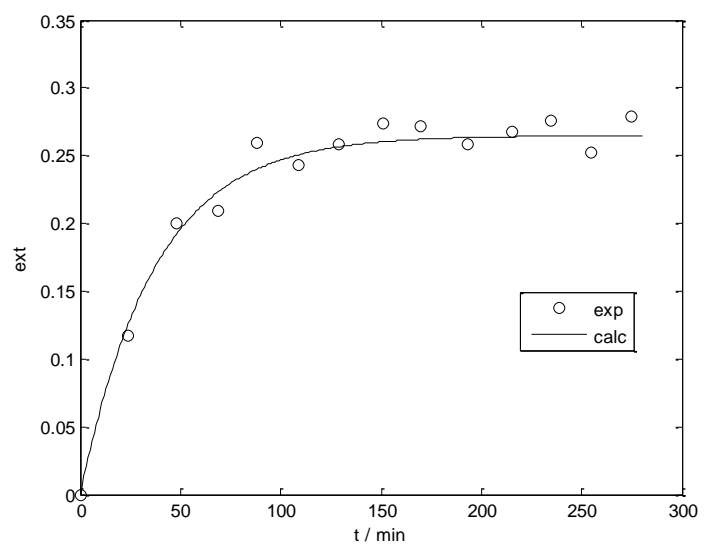

Figura 1 - Fração de óleo extraída em função do tempo.

Ao se observar os pontos experimentais representados na Figura 1, nota-se que os mesmos poderiam ser aproximados por uma função exponencial, como aquela sugerida na Equação 4.

$$
e x t=a_{1}\left(1-e^{a_{2} t}\right)
$$

Os coeficientes $a_{1}$ e $a_{2}$ devem ser determinados de modo que a Equação 4 represente bem o comportamento dos dados experimentais. Para isso, foi utilizado o método dos mínimos quadrados, de modo a minimizar o desvio entre os pontos experimentais e os previstos pela Equação 4. Obteve-se um valor de $a_{1}$ igual a 0,2648 e um valor de $a_{2}$ de $0,0269 \mathrm{~min}^{-1}$. O coeficiente $a_{1}$ está relacionado à fração máxima de óleo extraído, resultando numa porcentagem de cerca de $26,5 \%$, um valor um pouco abaixo daquele que se encontra em literatura. O inverso do coeficiente $a_{2}$, ou 37,2 min, é a constante de tempo desse processo de extração. Além disso, pode-se observar também que a fração máxima de óleo extraído é obtida em aproximadamente $200 \mathrm{~min}$, ou cerca de 3,5 horas. O óleo de 
girassol extraído foi caracterizado, obtendo-se um índice de acidez de 1,86 mg KOH/g e um índice de saponificação de 193,13 mg KOH/g. Esses valores indicam que a massa molar do óleo de girassol é de $879,61 \mathrm{~g} / \mathrm{mol}$.

A solução de hexano e óleo, proveniente da extração, foi transesterificada (seção 2.4), nas condições especificadas no planejamento experimental descritas na seção 2.5. A escolha dos níveis das variáveis estudadas foi feita com base em trabalhos que relatam a busca das condições ótimas de operação para a combinação de diferentes ácidos graxos de origem vegetal com diferentes alcoóis como metanol e etanol (Novazzi et al., 2008; Marin et al., 2008, etc.). Na Tabela 2 são apresentados, para cada ensaio de extração, os valores de massa de semente $m_{1}$ e da massa de óleo extraído $m_{2}$. Também são indicadas a relação molar metanol / óleo $\left(x_{1}\right)$ e a quantidade de catalisador $\left(x_{2}\right)$ utilizadas nas reações de transesterificação, assim como os rendimentos $y$ obtidos, com base nos ésteres metílicos formados.

Tabela 2 - Efeito da relação metanol / óleo e quantidade de catalisador sobre o rendimento da reação

\begin{tabular}{cccccc}
\hline Ensaio & $m_{1} / \mathrm{g}$ & $m_{2} / \mathrm{g}$ & $x_{1}$ & $x_{2} / \%$ & $y / \%$ \\
\hline A & 55,94 & 14,82 & $5: 1$ & 0,75 & 13,17 \\
B & 66,34 & 17,58 & $7: 1$ & 0,75 & 0,95 \\
C & 56,12 & 14,87 & $5: 1$ & 1,25 & 34,13 \\
D & 64,17 & 17,00 & $7: 1$ & 1,25 & 10,36 \\
& 38,79 & 10,28 & $6: 1$ & 1,00 & 12,99 \\
E & 38,90 & 10,31 & $6: 1$ & 1,00 & 12,80 \\
& 38,90 & 10,31 & $6: 1$ & 1,00 & 12,08 \\
\hline
\end{tabular}

Considerando-se o ensaio E, realizado em triplicata (Tabela 2), obtém-se uma estimativa de $0,48 \%$ para o desvio padrão $(s)$ e um valor de média igual a $12,62 \%$. Esse desvio permite avaliar estatisticamente se os efeitos principais e de interação são realmente significativos. Utilizando-se os valores de conversão dos ensaios expressos na Tabela 2 e levando-se em conta as Equações 1, 2 e 3, calculam-se os efeitos principais e os de interação, como indicados na Tabela 3. Observa-se que o aumento da relação molar metanol / óleo exerce um efeito negativo, enquanto que o aumento da quantidade de catalisador exerce um efeito positivo sobre o rendimento da reação. Analisando-se o valor de $R C$, também se vê que existe uma pequena interação entre as variáveis $x_{1}$ e $x_{2}$. Comparandose os resultados da Tabela 3 com o desvio padrão de 0,48\%, vê-se que os efeitos principais e de interação são relevantes.

Tabela 3 - Efeitos principais e de interação

\begin{tabular}{ccc}
\hline$R / \%$ & $C / \%$ & $R C / \%$ \\
\hline$-18,00$ & 15,19 & $-5,78$ \\
\hline
\end{tabular}

Além da análise dos efeitos, também foi proposto um modelo matemático empírico, que relacionasse o rendimento estimado da reação de transesterificação, $y_{c}$, com os efeitos $x_{1}$ e $x_{2}$. Tendose em conta que existe interação entre os efeitos, já que $R C$ é igual a $-5,78 \%$, propôs-se um modelo não linear, de segunda ordem, com coeficientes $a_{0}, a_{1}, a_{2}$ e $a_{3}$, conforme descrito na Equação 5. 


$$
y_{c}=a_{0}+a_{1} x_{1}+a_{2} x_{2}+a_{3} x_{1} x_{2}
$$

Os coeficientes $a_{0}, a_{1}, a_{2}$ e $a_{3}$, foram determinados pelo método dos mínimos quadrados, a fim de se minimizar a diferença quadrática entre $y$ e $y_{c}$. Os valores desses coeficientes são apresentados na Tabela 4.

Tabela 4 - Coeficientes $a_{i}$

\begin{tabular}{cccc}
\hline$a_{0}$ & $a_{1}$ & $a_{2}$ & $a_{3}$ \\
\hline$-31,43$ & 2,55 & 99,66 & $-11,55$ \\
\hline
\end{tabular}

Na Figura 2 apresenta-se um gráfico de paridade entre os resultados experimentais, $y$, e os resultados previstos pelo modelo, $y_{c}$. Pode-se notar que o ajuste foi muito razoável, com coeficiente de correlação de 0,997 .

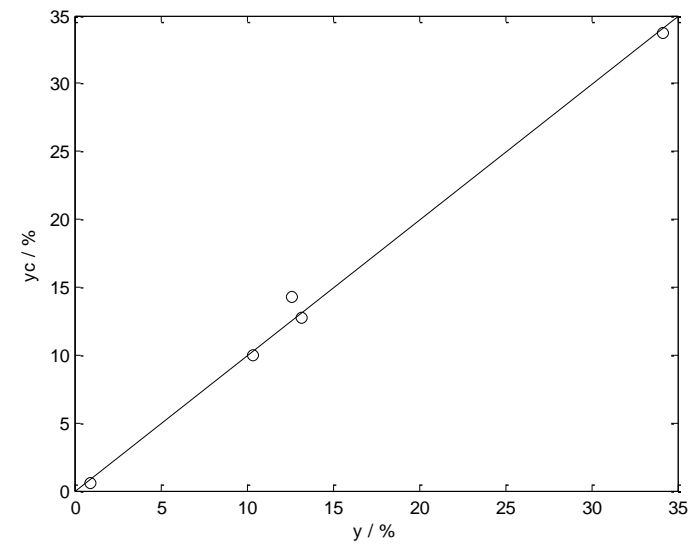

Figura 2 - Comparação entre o rendimento estimado e o experimental

\section{CONCLUSÃO}

Neste projeto estudou-se a reação de transesterificação associada a extração de óleo da semente de girassol. Foi verificado que para obter semente praticamente isenta de umidade são necessários pelo menos 4 horas de secagem em estufa a vácuo. No desenvolvimento deste trabalho optou-se em realizar a secagem por 5 horas. Determinou-se que o teor de óleo contido na oleaginosa em estudo é em torno de 26,5\% e que são necessárias 3,33 horas para se atingir a condição de máxima extração.

Foi utilizado um planejamento fatorial $2^{2}$ com ponto central para a análise da influência das variáveis estudadas e constatou-se que o rendimento diminui em média $18,00 \%$ quando a relação molar metanol-óleo passa do seu nível inferior para o superior. O rendimento aumentou em média $15,19 \%$ quando a quantidade de catalisador $(\mathrm{KOH})$ passou de seu nível inferior para o nível superior. Verificou-se também que há um efeito de interação entre as variáveis e que tanto os efeitos principais como o de interação foram estatisticamente significativos. Foi proposto um modelo matemático de segunda ordem (Equação 5), que representasse o rendimento da reação em função da relação molar metanol / óleo e da quantidade de catalisador, obtendo-se uma boa aproximação (Figura 2). Concluiu-se também que a razão volumétrica elevada entre o co-solvente e o metanol, de 250 para 1 , 
interferiu na reação de transesterificação, sendo a hipótese que justificaria os baixos graus de conversão obtidos.

\section{AGRADECIMENTOS}

Os autores agradecem todo apoio institucional oferecido pelo Centro Universitário da FEI.

\section{REFERENCIAS}

AOCS. Method Ca 5a-40: Free Fatty Acids, Official Methods Recommended Practices of the American Oil Chemist's Society, 5 ed. Illinois: American Oil Chemists' Society, 1998.

AOCS. Method Ca 3b-76: Free Fatty Acids, Official Methods Recommended Practices of the American Oil Chemist's Society, 5 ed. Illinois: American Oil Chemists' Society, 1998.

BRUM, A. A. S.; ARRUDA, L. F.; REGITANO d'ARCE, M. A. B. Método de extração e qualidade da fração lipídica de matérias-primas de origem vegetal e animal. Química Nova, 2009.

BRUNS, R. E.; BARROS, B.; SCARMINIO, I. S. Como Fazer Experimentos: Pesquisa e Desenvolvimento na Ciência e na Indústria. Campinas: Editora da UNICAMP, 2001.

GUIRRA, F. Uma Fonte Promissora. Biodiesel br, ano 2, n. 9, p. 40 - 47, 2009.

KNOTHE, G.; GERPEN, J.V.; KRAHL, J.; RAMOS, L.P. Manual do Biodiesel. 1 ed. Rio de Janeiro: Editora Edgar Blücher, 2006.

MARIN, M. P. A.;BERTEVELLO, L. C.; BARBOSA, E.; ROSENCRANTZ, L. H.; ZANCO, N. A. Influência nas Variáveis de Processo na Transesterificação do Óleo de Mamona. Anais do XVII COBEQ, 2008.

MEHER, L. C.; SAGAR, D.V.; NAIK, S. N. Technical aspects of biodiesel production by transesterficaton - review. Renewable \& Sustainable Energy Reviews, v.10, p.248-268, 2006.

NOVAZZI, L. F.; TAVARES, L.; LUCCA, E. Produção de Biodiesel a partir da Transesterificação Etílica do Óleo de Soja. Anais do XVII COBEQ, 2008.

SANTOS, S. L.; FERREIRA, M. S.; MARIN, M. A. P.; NOVAZZI, L. F. Use of Hydrodynamic Cavitation as an Alternative for Biodiesel Production. Proceedings of the $22^{\text {nd }}$ ECOS, 2009.

SHI, H.; BAO, Z. Direct Preparation of Biodiesel from Rapeseed Oil leached by Two-Phase Extraction. Bioresource Technology, v.99, p.9025-9028, 2008.

TOMASEVIC, A. V.; SILER-MARINKOVIC, S. S. Methanolysis of used frying oil. Fuel Processing Technology, v.81, p. 1-6, 2003. 